\title{
Pengaruh Current Ratio terhadap Return on Assets pada Bumdesa Lancang Kuning Desa Rumbai Jaya Kecamatan Kempas Kabupaten Indragiri Hilir Riau
}

\author{
Suharmiyati ${ }^{1^{*}}$, Yenny Iskandar ${ }^{2}$ \\ ${ }^{1,2}$ Program Studi Manajemen, Sekolah Tinggi Ilmu Ekonomi Indragiri (STIE-I) Rengat \\ *Correspondence email: suharmiyati@stieindragiri.ac.id, 2yennyiskandar@stieindragiri.ac.id.
}

\begin{abstract}
This research is done in BUMDesa Lancang Kuning village Rumbai Jaya Kempas Sub-district of Indragiri Hilir. This research aims to determine the influence of current ratio of return on assets on Bumdesa Lancang Kuning village of Tassel Jaya Kempas District of Indragiri Hilir Bumdesa Lancang kuning Village Tassel Jaya Kempas Sub District Indragiri Hilir is a stateowned business entity that aims to improve the economy of society, especially the village community of Tassel Jaya. And analysis of data used simple linear regression, f test, and Test T. From the results of the research can be seen that the results of the Current Ratio variable test is partially obtained that the < Ttabel Thitung, so that the Current Ratio has not been a significant effect on Return On Assets in the BUMDesa Lancang Kuning village Rumbai Jaya Kempas District, Indragiri Hilir And there is medium relationship between Current Ratio against Return On Assets.
\end{abstract}

Keyword: Current ration, return on assets

\section{Pendahuluan}

BUMDesa Lancang Kuning Desa Rumbai Jaya Kecamatan Kempas Kabupaten Indragiri Hilir adalah badan usaha milik pemerintah yang bertujuan untuk meningkatkan perekonomian masyarakat khususnya masyarakat desa rumbai jaya. Perusahaan yang mampu memberikan keuntungan serta meningkatkan kemakmuran bagi pengelolanya adalah perusahaan yang berhasil dalam mencapai tujuan bisnisnya. Ciri-ciri perusahaan yang baik adalah perusahaan yang memiliki profitabilitas yang baik, Oleh karena itu perusahaan dituntut harus selalu menjaga kondisi profitabilitasnya agar dapat stabil sehingga investor akan tertarik untuk berinvestasi pada perusahaan tersebut. Kondisi Current Ratio pada BUMDesa Lancang Kuning Desa Rumbai Jaya Kecamatan Kempas Kabupaten Indragiri Hilir Riau pada tahun 2013 s/d 2018 dapat dilihat pada tabel berikut.

Tabel 1

Kondisi Current Ratio pada BUMDesa Lancang Kuning Desa Rumbai Jaya Kecamatan Kempas Kabupaten Indragiri Hilir Riau pada tahun 2013 s/d 2018

\begin{tabular}{crrrr}
\hline Tahun & Aktiva Lancar & Utang Lancar & Current Ratio & \multicolumn{1}{c}{ Persentase Pertumbuhan } \\
\hline 2013 & $604.757 .225,00$ & $507.866 .700,00$ & 1,19 & 0,00 \\
2014 & $781.181 .162,00$ & $624.136 .343,00$ & 1,25 & $5 \%$ \\
2015 & $931.306 .478,00$ & $716.828 .181,00$ & 1,30 & $4 \%$ \\
2016 & $859.523,000,00$ & $234.342 .000,00$ & 3,67 & $182 \%$ \\
2017 & $1.708 .789 .951,00$ & $573.297 .000,00$ & 2,98 & $-19 \%$ \\
2018 & $1.826 .056 .131,00$ & $681.918 .253,00$ & 2,68 & $-10 \%$ \\
\hline
\end{tabular}

Sumber: $\quad$ BUMDesa Lancang Kuning Desa Rumbai Jaya Kecamatan Kempas Kabupaten Indragiri Hilir Riau, Tahun 2020.

Untuk mengetahui Return On Assetspada BUMDesa Lancang Kuning Desa Rumbai Jaya Kecamatan Kempas Kabupaten Indragiri Hilir Riau pada tahun 2013 s/d 2018 dapat dilihat pada tabel berikut:

Tabel 2

Kondisi Return On Assets pada BUMDesa Lancang Kuning Desa Rumbai Jaya Kecamatan Kempas Kabupaten Indragiri Hilir Riau pada tahun 2013 s/d 2018

\begin{tabular}{lrrrr}
\hline Tahun & \multicolumn{1}{c}{ Laba Bersih } & \multicolumn{1}{c}{ Total Aktiva } & Return On Assets & Persentase Pertumbuhan \\
\hline 2013 & $63.940 .919,00$ & $605.702 .361,00$ & 0,11 & 0,00 \\
2014 & $95.612 .801,00$ & $781.181 .162,00$ & 0,12 & $16 \%$ \\
2015 & $120.333 .455,00$ & $931.306 .478,00$ & 0,13 & $6 \%$ \\
2016 & $117.912 .320,00$ & $859.523 .000,00$ & 0,14 & $6 \%$ \\
2017 & $121.895 .379,00$ & $1.717 .414 .951,00$ & 0,07 & $-50 \%$ \\
2018 & $151.480 .540,00$ & $1.826 .056 .131,00$ & 0,08 & $14 \%$ \\
\hline
\end{tabular}

Sumber: BUMDesa Lancang Kuning Desa Rumbai Jaya Kecamatan Kempas Kabupaten Indragiri Hilir Riau, Tahun 2019. 
Tujuan Penelitian ini adalah untuk mengetahui pengaruh Current Ratio secara parsial terhadap Return On Assets pada BUMDesa Lancang Kuning Desa Rumbai Jaya Kecamatan Kempas Kabupaten Indragiri Hilir Riau.

\section{Telaah Pustaka dan Hipotesis \\ Return On Assets}

Return On Assets adalah hasil pengembalian atas aset merupakan rasio yang menunjukkan seberapa besar kontribusi aset dalam menciptakan laba bersih. Dengan kata lain, rasio ini digunakan untuk mengukur seberapa besar jumlah laba bersih yang akan dihasilkan dari setiap rupiah dana yang tertanam dalam total aset. Rasio ini dihitung dengan membagi laba bersih terhadap total aset. (Hery, 2016). Return On Asset mengukur kemampuan perusahaan dalam memanfaatkan aktivanya untuk memperoleh laba. (Prastowo,et.al, 2008). Return On Assets mengukur kemampuan perusahaan menghasilkan laba bersih berdasarkan tingkat aset yang tertentu. (Mamduh, 2009). Return On Assets merupakan rasio profitabilitas yang digunakan untuk mengukur efektifitas perusahaan didalam menghasilkan keuntungan dengan memanfaatkan total aktiva yang dimilikinya. Semakin besar menunjukkan kinerja perusahaan semakin baik. (Rahmawati, 2011). Return On Assets menunjukkan kemampuan perusahaan dalam menghasilkan laba dari aktiva yang digunakan. (Home,et.al, 2009). Return On Assets adalah Rasio yang mengukur kemampuan perusahaan menghasilkan laba bersih berdasarkan tingkat aset yang tertentu. Return On Assets juga sering disebut sebagai Return on Investement. Rasio yang tinggi menunjukkan efisiensi manajemen aset, yang berarti efisiensi manajemen. Rumus yang digunakan untuk menghitung Return On Assets yaitu: (Subramanyam, 2010)

Return On Assets $=\frac{\text { Laba Bersih }}{\text { Total Aset }}$

\section{Current Ratio}

Rasio lancar (Current Ratio) merupakan rasio untuk mengukur kemampuan perusahaan dalam membayar kewajiban jangka pendek atau utang yang segera jatuh tempo pada saat ditagih secara keseluruhan. Dengan kata lain, seberapa banyak aktiva lancar yang tersedia untuk menutupi kewajiban jangka pendek yang segera jatuh tempo. Rasio lancar dapat pula dikatakan sebagai bentuk untuk mengukur tingkat keamanan (margin of safety) suatu perusahaan. (Kasmir, 2013). Current Ratio merupakan rasio yang digunakan untuk mengukur kemampuan perusahaan dalam memenuhi kewajiban jangka pendeknya yang segera jatuh tempo dengan menggunakan total aset lancar yang tersedia. (Hery, 2016). Rasio lancar mengukur kemampuan perusahaan memenuhi kewajiban jangka pendeknya dengan menggunakan aktiva lancarnya. (Mamduh, et.al, 2009). Current Ratio menunjukkan sejauh mana aktiva lancar menutupi kewajiban-kewajiban lancar. Semakin besar perbandingan aktiva lancar dan kewajiban lancar semakin tinggi kemampuan perusahaan menutupi kewajiban jangka pendeknya. Current ratio yang rendah biasanya dianggap menunjukkan terjadinya masalah dalam likuidasi, sebaliknya current ratio yang terlalu tinggi juga kurang bagus, karena menunjukkan banyaknya dana menganggur yang pada akhirnya dapat mengurangi kemampu labaan perusahaan. (Sawir, 2009). Rumus untuk mencari Current Ratio atau rasio lancar yang dapat digunakan sebagai berikut: (Kasmir, 2013).

Current Ratio $=\frac{\text { Aktiva Lancar }}{\text { Utang Lancar }}$

\section{Hipotesis}

Diduga Current Ratio berpengaruh terhadap Return On Assets pada BUMDesa Lancang Kuning Desa Rumbai Jaya Kecamatan Kempas Kabupaten Indragiri Hilir Riau.

\section{Metode}

Penelitian ini langsung pada BUMDesa Lancang Kuning Jl. Pelabuhan Samudra Blok C Desa Rumbai Jaya Kecamatan Kempas Kabupaten Indragiri Hilir Riau. Penelitian ini dilakukann selama 6 bulan. Metode pendekatan yang digunakan dalam penelitian ini adalah metode kuantitatif, yaitu penelitian yang menggambarkan tentang Current Ratio terhadap Return On Assets pada BUMDesa Lancang Kuning Desa Rumbai Jaya Kecamatan Kempas Kabupaten Indragiri Hilir Riau.

\section{Analisis Regresi Linear Berganda}

Analisis Regresi Linear Berganda digunakan untuk mengukur pengaruh antara lebih dari satu variabel bebas (variabel $\mathrm{X})$ terhadap variabel terikat (Variabel Y).

$\mathrm{Y}=\mathrm{a}+\mathrm{bX}+\mathrm{e}$

Uji yang dilakukan untuk uji hipotesis ini adalah uji $t$

Dimana:

$\mathrm{Ho}=\mathrm{b}=0$ Current Ratio tidak berpengaruh signifikan terhadap Return On Assets.

$\mathrm{Ha}=\mathrm{b} \neq 0$ Current Ratio berpengaruh signifikan terhadap Return On Assets. 
Suharmiyati dan Yenny Iskandar, Pengaruh Current Ratio Terhadap Return On Assets pada Bumdesa Lancang Kuning Desa Rumbai Jaya Kecamatan Kempas Kabupaten Indragiri Hilir Riau

Apabila $\mathrm{t}$ hitung $>\mathrm{t}$ tabel artinya Ha diterima dan Ho ditolak atau tidak sama dengan 0 artinya ada pengaruh yang signifikan antara variabel $\mathrm{X}$ dan Variabel $\mathrm{Y}$

Apabila $\mathrm{t}$ hitung $<\mathrm{t}$ tabel artinya Ha ditolak dan Ho diterima atau sama dengan 0 artinya tidak ada pengaruh yang signifikan antara variabel $\mathrm{X}$ dan Variabel Y.

\section{Hasil}

Tabel 3

Coefficients

\begin{tabular}{|l|r|r|r|r|r|}
\hline \multirow{2}{*}{ Model } & \multicolumn{2}{|c|}{ Unstandardized Coefficients } & Standardized Coefficients & \multirow{2}{*}{ Sig. } \\
\cline { 2 - 5 } & B & Std. Error & Beta & 1,023 &, 083 \\
\hline (Constant) &, 010 &, 120 &, 939 &, 740 &, 513 \\
Current Ratio &, 027 &, 036 & & & \\
\hline
\end{tabular}

Sumber: data olahan

Persamaan Regresinya sebagai berikut:

$\mathrm{Y}=0,010+0,027 \mathrm{X} 1$

Konstanta sebesar 0,010; Artinya nilai konstanta ini menunjukkan bahwa apabila variabel Current Ratio (X1) dan Debt To Equity Ratio (X2) nilainya adalah 0, maka Return On Assets (Y) nilainya adalah 0,010.

Koefisien regresi variabel Current Ratio (X1) sebesar 0,027,Artinya jika variabel Current Ratio mengalami kenaikan 1 satuan dan Debt To Equity Ratio tetap, maka Return On Assets (Y) akan meningkat sebesar 0,027.

Tabel 4

Model Summary

\begin{tabular}{|l|r|r|r|r|c|}
\hline Model & \multicolumn{1}{|c|}{$\mathrm{R}$} & \multicolumn{1}{c|}{ R Square } & Adjusted R Square & Std. Error of the Estimate & Durbin-Waston \\
\hline 1 &, $509^{\mathrm{a}}$ &, 259 &,- 236 &, 03098 & 1,537 \\
\hline
\end{tabular}

Sumber: data olahan

Berdasarkan Tabel 4 diatas diperoleh angka $\mathrm{R}^{2}$ (R Square) atau disebut koefisien determinasi adalah sebesar 0,259 artinya $25,9 \%$. Menunjukkan persentase sumbangan variabel independen (Current Ratio) terhadap variabel dependen (Return On Assets) atau variasi variabel independen yang digunakan dalam model (Current Ratio) mampu menjelaskan sebesar $25,9 \%$. Sedangkan sisanya sebesar $74,1 \%$ dipengaruhi atau dijelaskan oleh variabel lain yang tidak diteliti dalam penelitian ini.

\section{Uji Hipotesis}

Tabel 3 diatas, dapat dilihat nilai t-hitung dari variabel bebas, yaitu Current Ratio dan t-tabel dapat diketahui menunjukkan bahwa variabel Current Ratio (X1) diperoleh nilai t-hitung sebesar 0,740'karena nilai t-hitung < t-tabel $(0,740$ < 2,776) maka Current Ratio (X) tidak berpengaruh signifikan terhadap Return On Assets (Y). Hal ini mengindikasikan bahwa hipotesis pada penelitian ini Ho diterima dan Ha ditolak.

\section{Simpulan}

Hasil pengujian variabel Current Rasio dapat bahwa t-hitung $<\mathrm{t}$-tabel, sehingga Current Ratio secara tidak berpengaruh signifikan terhadap Return On Assets pada BUMDesa Lancang Kuning Desa Rumbai Jaya Kecamatan Kempas Kabupaten Indragiri Hilir Riau.

\section{Daftar Pustaka}

Harahap, S.S, 2013, Analisis Kritis atas Laporan Keuangan, Jakarta, Raja Grafindo Persada.

Hanafi, Mamduh M. dan Abdul Halim. 2014,Analisis Laporan Keuangan, Yogyakarta : Penerbit UPP STIM YKPN.

Hantono, Teng Sauh Hwee, 2017,Pengaruh Likuiditas, Ukuran Perusahaan, Leverage Terhadap Profitabilitas Dengan Corporate Social Responsibility Sebagai Variabel Intervening Pada Perusahaan Consumer Goods Yang Terdaftar Di Bursa Efek Indonesia,Faculty of Economi,.Departement of Accounting,Universitas Prima,Indonesia.

Herman Supardi, H. Suratno, Suyanto, 2016,Pengaruh Current Ratio, Debt To Asset Ratio, Total Asset Turnover Dan Inflasi Terhadap Return On Asset, Program Magister Akuntansi Universitas Pancasila.

Hery, 2016, Analisis Laporan Keuangan, Jakarta : Penerbit PT Granmedia Widiasarana Indonesia.

http://duwiconsultant.blogspot.com/2011/11/analisis-korelasisederhana.html?m=1

https://repository.widyatama.ac.id > handle 
Horne, James C. Van dan John M. Wachowicz, 2012, Prinsip-prinsip Manajemen Keuangan. Jakarta: Salemba Empat. Mahardhika, Marbun, 2016,Pengaruh Current Ratio Dan Debt To Equity Ratio Terhadap Return On Assets,Program Studi Manajemen, Universitas Pembangunan Jaya.

Mamduh M, Hanafi dan Abdul, Halim, 2009,Analisis Laporan Keuangan. Yogyakarta : UPP STIM YKPN.

Kasmir, 2013,Analisis Laporan Keuangan,PT RajaGrafindo Persada, Jakarta.

Murhadi, Werner, 201, Analisis Laporan Keuangan Proyeksi dan Valuasi Saham, Jakarta : Penerbit Salemba Empat.

Prastowo, Dwi dan Rifka, Juliaty, 2008, Analisis Laporan Keuangan, Yogyakarta. Sekolah Tinggi Ilmu Manajemen

Prihadi, Toto, 2013,Analisis Laporan Keuangan: Teori dan Aplikasi, Jakarta Pusat: Penerbit PPM.

Rahmawati, Fitri Linda, 2011, Pengaruh Current Ratio, Inventory Turnover dan Debt to Equity Ratio Terhadap Return On Assets, Universitas NegeriMalang, Malang, Diunduh tanggal 20 Juni 2013

Sawir, Agnes, 2009,Analisis Kinerja Keuangan Teori dan Perencanaan Keuangan Perusahaan,Jakarta : PT.Gramedia Pustaka Umum.

Subramanyam, K.R, 2010,Analisis Laporan Keuangan, Jakarta: Salemba Empat.

Sudana, I Made, 2011,Manajemen KeuanganPerusahaan Teori dan Praktek, Jakarta: Erlangga.

Sunyoto, Danang, 2013,Analisis Laporan Keuangan untuk Bisnis (Teori dan Kasus), Cetakan 1. Yogyakarta : Penerbit CAPS. 